\title{
Avaliação Clinica e Urodinâmica de Mulheres com Instabilidade Vesical Antes e Após Eletro- estimulação Funcional do Assoalho Pélvico
}

\author{
Autora: Raquel Martins Arruda \\ Orientadora: Prof. Dr. Manoel João Batista Castello Girão
}

Tese apresentada à Universidade Federal de São Paulo- Escola Paulista de Medicina para obtenção do Título de Mestre em Ginecologia em 15 de junho de 2000.

Selecionamos 29 mulheres com diagnóstico de instablidade vesical. Avaliamos de forma subjetiva e objetiva (estudo urodinâmico), os efeitos da eletroestimulação funcional do assoalho pélvico no tratamento desta afecção. As pacientes submeteram-se a duas sessões semanais de eletro-estimulação vaginal, cada uma durando vinte minutos, por período de três meses consecutivos. A intensidade da corrente variou de 10 a $100 \mathrm{~mA}$, de acordo com a tolerância de cada paciente. A freqüência utilizada foi de $20 \mathrm{~Hz}$ e a duração do pulso foi de $1 \mathrm{mseg}$. Após o tratamento, 75,85\% das pacientes consideravam-se curadas ou melhoradas e apenas $24,13 \%$ delas se sentiam insatisfeitas com a terapia empregada. Pelo estudo urodinâmico observamos que em $34,5 \%$ das cistometrias houve cura objetiva após a terapia empregada, melhora em 27,6\% dos casos, e, em 37,9\%, o exame permaneceu inalterado. Com relação à urgência miccional, 41,4\% das pacientes que apresentavam este sintoma antes do tratamento referiram desaparecimento do mesmo após a eletro-estimulação. Neste estudo, notamos ainda diminuição gradativa do número de episódios de perda urinária. $\mathrm{Na}$ avaliação urodinâmica, houve aumento significativo das capacidades cistométrica máxima e no primeiro desejo miccional bem como do volume urinário após a eletroterapia. Concluímos que a eletroestimulação funcional do assoalho é efetiva no tratamento de mulheres com instabilidade vesical. As modificações clínicas e urodinâmicas foram evidentes. Trata-se de uma forma de tratamento simples, eficaz e com pequena incidência de efeitos colaterais.

Palavras-chave: Eletro-estimulação. Incontinência urinária de esforço.

\section{Isoformas de Prolactina no Fluido Folicular de Pacientes Submetidas a FIV}

Autor: Gustavo Salata Romão

Orientador: Prof. Dr. Rui Alberto Ferriani

Tese de Doutorado apresentada ao Departamento de Ginecologia e Obstetrícia da Faculdade de Medicina de Ribeirão Preto da Universidade de São Paulo em 20 de dezembro de 1999.

Objetivos: Este estudo teve por finalidade o isolamento e a caracterização das isoformas de prolactina (PRL) no fluido folicular de mulheres submetidas a fertilização in vitro (FIV).

Métodos: Entraram para este estudo 19 pacientes submetidas a FIV no Hospital das Clínicas de Ribeirão Perto entre novembro de 1997 e julho de 1998. As amostras de fluido folicular foram obtidas durante a captação de oócitos. Para a identificação das isoformas de PRL nessas amostras procedeu-se à separação das mesmas em cromatografia de filtração em gel Sephacryl S-200 HR seguida de detecção por quimioluminescência nas frações do eluato. Os pesos moleculares das isoformas presentes no fluido folicular foram estimados a partir do Diagrama de Andrews que correlaciona os pesos moleculares de padrões conhecidos (Blue Dextran, $\mathrm{NaCl}$, Soroalbumina Bovina, Quimiotripsinogênio, Ovoalbumina e Ribonuclease) com seus respectivos volumes de detecção nas frações do eluato.

Resultados: A principal isoforma de PRL detectada nas amostras de fluido folicular foi a Small PRL, com peso molecular em torno de $22,8 \mathrm{kD}$.

Conclusão: A small PRL parece ser a principal isoforma presente no fluido folicular de pacientes submetidas a FIV. O significado clínico destes achados parece relevante uma vez que a small PRL é biologicamente mais ativa que as demais.

Palavras-chave: Prolactina. Folículo ovariano. Fertilização in vitro. 